\title{
Women in Indian Information Technology (IT) sector: a Sociolog- ical Analysis
}

\author{
${ }^{1}$ Asmita Bhattacharyya, ${ }^{2}$ Dr. Bhola Nath Ghosh \\ ${ }^{1}$ Senior Research Fellow, Sociological Research Unit, Indian Statistical Institute, Kolkata 100203 \\ ${ }^{2}$ Assistant Professor, Sociological Research Unit, Indian Statistical Institute, Kolkata 100203
}

\begin{abstract}
The emergence of Information Technology sector in mid-1990s has unveiled a potential employment opportunity for women in this organized sector congenially befitting their job environment and offering, in principle, least gender discrimination. This paper attempts to analyze the issues of opportunities and constraints the women employees face in the Information Technology sector in India. IT sector, through its employment, contributes substantially to women empowerment. Its employment potentiality provides inspiration to female students to take up technical and professional courses with an eye to the job market. Most reviews reveal that, notwithstanding overall satisfactory gender neutral pursuit by this sector, an optimal level of gender inclusivity is still to be achieved, especially to the senior level. Moreover, this sector requires to be extra-careful in doing away with the prevailing maladies such as 'Feminization', 'Glass ceiling' etc. The theoretical aspect of individualization in the workplace is palpable but at the societal level, patriarchal strategies dominate on the Indian psyche. The reflection of this paper is arrived at, on the basis of, the inputs drawn from different literatures of secondary sources.
\end{abstract}

Keywords- Feminization, Gender discrimination, 'Glass ceiling', Information Technology and women employees face.

\section{Introduction}

Globalization has made deep inroads in the Indian scene in post-1990s. It sets off, inter-alia, market liberalization and emergence of Information Technology (IT) sector. Development of Information Technology (ICT) ${ }^{1}$, in recent decades, facilitated by the high-speed data communication links, contributed to improved communicative networks bridging the temporal and spatial boundaries and, correspondingly, widened the scope of opportunities for people seeking paid work. The onset of Liberalisation and Globalisation in 1990s paved the way for growth of IT industry in India. IT industry enjoys natural comparative advantage of 12 hour time-gap with most of the overseas countries, exposure to a large cross- section of educated English-speaking but cheap labour force and, above all, Indian Government's policy incentives e.g. setting up of several Software Technology Parks (STPs) and providing tax holidays to profit making IT industry etc. Besides boosting up export earning for the country and creating a new pool of entrepreneurs, IT sector has its inherent spillover benefit of creating employment potential for a large pool of educated unemployed youths including an attractive option for the women. It is worth mentioning that IT industry has now captured about 51 per cent of the world market (Kumar 2001). National Association of Software Services Company (NASSCOM)-Mencher- Report 2009, on the other hand, has revealed that over the years the proportion of women workforce at entry level as well as middle level management has increased considerably but there is lack of adequate representation of women at the senior level.

This paper attempts to get into the theoretical underpinning having emerged from the overview of literatures on women working in this high-tech industry in India. To start with, a probe into the secondary literatures is taken into consideration for the questions raised in the objectives of the paper. The paper summarises the threads of arguments that follow in the discussion section of the paper. Finally, it wraps up conclusion after providing some vital leads for comprehensive future research.

\section{Objectives:}

The current paper tries to address the following two objectives:

2.1. Does the development of IT in India enable woman of being empowered? If so, what are the contexts that influence the same?

2.2. What kind of constraints, if any, do the women face in their workplace? 


\section{Literature Review \\ 3.1 Opportunities provided for women by IT}

The secondary literatures used, as the source of discussion, to outline the opportunities that IT sector has created for women employees and to gauge the extent to which same has been materialised/percolated to the beneficiaries.

Employment opportunities in IT Sector: The Indian IT-BPO industry has emerged as the largest private sector employer in the country with direct employment of about 2.23 million professionals. The percentage of female employees, over the years, has steadily increased from 35\% in 2006 to $36 \%$ in 2008 at the junior level (NASSCOM-Mencher, 2009).

The important factors that encourage women workforce to participate in IT sector are for embracing a white-collar job with comparatively high salary, easy international mobility, gender-neutral policy based on knowledge-centric skills possession, flexible work routine and physically less demanding work process in comfortable indoor work- environment (Kumar 2001; Upadhya 2006; Shanker 2008).

The gateway of getting into this sector is through higher and technical education. As such, growing female participation rate in this sector has raised the claim that it has encouraged women into professional, technical and higher education. High employment potentiality in this industry inspired a large number of girls to go for professional education, especially for the computer engineering courses. It transpires from the NASSCOMMencher, 2009 report that only 5 to 8 per cent of female engineering graduates were in the IT industry during 1980s whereas this figure has shot up drastically to 20 to 30 per cent currently.

The studies of different social effects on the participation of women workforce in IT industry located in Delhi and Bangalore are being discussed. Kelkar et al. 2002 observed that women working in this sector become socially mobile to live in other cities away from their male relatives and families for the sake of their jobs. They no longer constrain themselves to opt for jobs which are near to their home town alone. Direct opportunities offered by the IT industry for advancement of women's careers increases the agency i.e. they take decisions of their own and within limited terms. Kelkar and Nathan (2002) observe that the effects of women's entry into the IT Sector have augmented their household income enlarging their bargaining power within the households. Besides, larger quantum of work participation rate among the women furthers their social mobility. In IT sector, Individualisation capacities are enhanced as the women employees need to make decisions very often on their own and that too instantly, thus, offering greater scope for boosting up their agency. This, in turn, helped in redefining the traditional gender norms. The study of Clark and Sekher (2007) has drawn inference that flexibilised labour market in this high tech sector improves women employees' financial autonomy, greater mobility and their larger social acceptance in male dominated society. Like Clark et al. Shanker's study (2008) asserts that IT industry is the destination of the 'privileged'- young, educated, urban and upper caste with middle class family background- constitute the majority of the workforce. She further observes that women professionals have enhanced their social status in terms of having economic capital (high income, foreign travels), social capital (role model and greater prospects of marriage) and symbolic capital (prestige attached to profession).

But 'achievement' is selective. It has not been possible for the women in the IT sector to challenge the structural inequalities and gender relations respectively at the work place and at home. As a result, an ongoing struggle brews in on them to challenge the embedded patriarchal relations and existing structural inequalities. Yet, women do not hesitate to seek constantly to balance work and domestic responsibilities with little help from their men (Kelkar and Nathan 2002; Shanker 2008).

It, therefore, raises the next part of the question as to what kind of gender relation, women in IT, face at the work-place where gender neutral and 'Equal opportunity policy' are due to be followed as the Human Resource Policy.

\subsection{Glass Ceiling, Feminisation and associated constraints make IT a Gendered Workplace:}

Studies $^{2}$ underline the existence of feminisation or 'glass- ceiling ${ }^{3}$ in this industry; since the women workforce gets concentrated mostly at the lower level of job hierarchy in the IT sector. But at the senior level, women representation is only around 5 per cent. The reasons attributed to this are: (a) stereotyped female professional (b) personal sense of mid-career guilt and (c) proverbial 'glass ceiling' (NASSCOM-Mencher report 2009). A small percentage of women are in the managerial position. A few women work as Software developers, Architectures, Tech leads, Consultants or Project managers whereas a bulk of them works at the lower level as testers, programmers or quality assurances and such other low-end jobs. They are, thus, paid less and have fewer channels of growth and lesser chance of going abroad. Women, thus, cluster at the lower level of jobladder leading to eminisation of certain service activities and consequential segregation. Very few women reach the higher level of managerial jobs (Kelkar et al. 2002; Upadhya 2006). Shanker (2008) echoed the same findings in Bangalore to the effect that women professionals were mostly concentrated at the entry and intermediate levels rather than flocking at the middle and upper ranks, thus, creating the glass-ceiling. 
Again, culturally there is persistence of gender-biased stereotypes practiced by the management for its ideological construction of women's skills as 'soft skills', being good at routine, standard and repetitive works. The notion shapes the recruitment practices. This, in turn, limits the opportunities for women's promotion. Reinforcement of gender based stereotypes creates a culturally and structurally defined glass-ceiling (Abraham 2008).

Women workforce in Information technology sector face glass- ceiling ${ }^{4}$ and is not able to rise high after certain level of hierarchy as they fail to bargain for proper perks, stock options, pay scales etc. Again, usually they fail to upgrade their skills; tend to remain attached to a particular company for a longer period rather than going for job hopping thus, stick to immobility (Shanker 2008). Failure to put up late hours to build informal networking debars them from getting information on career openings (Upadhya 2006). Their career choices are constrained by distance from home, domestic responsibilities, job securities, company reputation and for other social reasons.

The impression of 'stereotypical image' for women employees on the part of recruiters, team lead and male colleagues results in marginalisation of women at the workplace especially during the time of project deadlines (Upadhya 2006); other constraining factors include recruitment and promotion filters for selection of certain 'social types' (Shanker 2008), lack of mentors and want of network for women at higher position (Kelkar et al. 2002) etc. Non implementation of women sensitive flexi-time policy etc. further hampers promotional prospects of women software professionals (Upadhya 2006).

\section{Theoretical Framework: \\ Prominence of Individualisation in the era of Globalisation:}

Friedman, 2006, coined Globalisation 3.0 for the period 2000 and onwards enabling individuals all over the world to become empowered as they began to realise that they had more power than ever to go global as individuals, had more opportunities for work and to think of themselves as individuals. This phase of Globalisation is distinctively different from Globalisation $1.0(1492-1800)$ when countries get globalised with other countries for the sake of trade. Globalisation 2.0 (1800-2000), on the other hand, encompasses the period from Industrial Revolution-to Colonisation-to Multi-National Companies (MNCs) going Global.

As we go through the literatures, we find that the Globalising forces have mediated changes at the Macro level or Societal layers; at Meso level i.e. the economic and political strata and at Micro level that includes change in identity at individual level.

4.1 Macro level: According to Anthony Giddens ${ }^{5}(1991,1994,2000)$ Globalising forces have influenced the transformation of Society from traditional to modern to high modern Society. The traditional Society or preindustrial Society predominantly based on communal structures, had the 'We' feeling. With the rise of modern structures and the associations based on shared interests in Modern Society, the 'We' feeling was replaced by a set of abstract, atomised individuals, thus, replacing the earlier Society. Scott, 1994, observes that the High modern society/risk- society ${ }^{6}$ again replaced the Modern Society with innovation of electronic communications systems and the Risk Society has set individuals free from modern abstract structures.

4.1.2 Society and individual identity: The very individual identity changes even with the change in the type of Society. In the Traditional Society, it is the collectivities like Group, Community etc. prescribe the individuals not only what 'is' done is done in the Society but 'what should be done' in a Society; hence, it is the collectivities that ascribe an identity to the individual and provide a framework of action structure for the present and organises the future. Therefore, it acts as the glue that holds the pre-modern social orders (Giddens 1994). The self identity in modern Society becomes more freed from traditional identities in terms of Kinship, Clan, Caste, family identities etc. with stress on atomisation and individuation. Here, 'Self ${ }^{7}$ is expressed in terms of ' what they do' and ' why they do it' giving routinisation a sense of trust or ontological security ${ }^{8}$ sustained in the daily activities (Giddens 1991). The third phase of the Society i.e. the High Modern Society/Risk Society is marked by Reflexive Modernisation which means self confrontation with the effects of risks ${ }^{9}$. It dissolves the traditional parameters of Class Culture and Consciousness, Gender and family roles. Reflexive Modernisation is a theory of ever-increasing powers of Social Actors ('free and knowledgeable agency') in regard to structure. The theory of Reflexive- Modernisation is a very strong programme of individualisation ${ }^{10}$. Beck's 'I am I' observation in which the 'I' is increasingly made free from communal ties and is able to construct his or her own biographical naratives (Scott 1994). Individual identity in post-traditional Society is dependent on 'Who are you and what do you want?' (Giddens 1994).

4.1.3 Meso Level: The post- Liberlisation era saw radical changes in Economy causing a corresponding change in Statism. The post liberalised Economy, better known as the 'New Economy', is the Economy of Internet Industry i.e. of dot.com firms. Here, Internet provided the medium of networking organisation, information- 
processing and knowledge generation. It has transformed the old Economy to its global reach with the capacity to work as a unit in real time on a planetary scale (Castells 2001). This form of Economic Globalisation leads to a major transformation in territorial organisation of economic activity with geographic dispersal of firms and factories and virtualisation of economic activities is evident from the growing number of economic activities taking place in electronic space (Sassen 2006). Castells (1997) termed the new system of business organisation as the 'Networ Enterprise' and is the situation where 'networking logic based on working on-line with the networked units in real time'. It advocates organisational flexibility of firms in contravention of rule-based mechanised Fordist structure. It encourages the deregulated, flexible post-Fordism way of production, management and marketing. Companies offer autonomy to workers by placing Toyatism ${ }^{11}$ over Toyalorism ${ }^{12}$ and demand more commitment for their business projects.

Similarly, the present Service Economy with flexible pattern of employment, destandarised worksites, labour laws and working hours are altogether different from the traditional economic firms /public sectors that follow standarised working hours, labour contract and workplace that follows a predictable career pattern, salarisation of work, socialisation of production, full-time employment and greater bargaining power of Labour Unions (Beck 1998). The phenomena impacts the nature of the State from Welfare State to deregulated [declining significance of State and dominance of role of World Trade Organisation (WTO)/ MNCs] and denationalised State resulting in undermining Sovereignty and exclusive territoriality of the State because of cross-border flows and global telecommunications (Sassen 2006).

4.1.4 Labour market and Individualisation: The de-traditionalised individuals of the High Modern Society are increasingly dependent on the labour market and the workforce becomes increasingly individualised. Beck, 1998, identifies the causes of individualisation of Service sector labour market in Germany as under:

a) Education: Educated persons aspiring for individualised career opportunities towards upward mobility in the labour market become critical on hierarchal model at the workplace and against their own labour situation.

b) Mobility: High mobility of the workforce leads to change of residence and employment. The resultant effect is the decline in social bonds with the family and the neighbourhood and increased dependence on Associations/Clubs.

c) Competition: Individuality and uniqueness of one's work and own accomplishments provide one's competitive edge among the equals leading to individualisation.

d) Collective upward mobility and higher standards of living: It refers to exclusive type of consumption and style of living, such as possession of private cars, undertaking of holiday travels etc. attaching an edge to an individual.

e) Juridification of labour relations: With decline in Trade Union Organisation activities led affected individuals to defend their rights directly in the Courts.

Castells (1997) also notes that the Network Enterprises give more autonomy to workers by decentralisation of work tasks, segmenting work and coordinating it in an interactive network of communication in real time. This sets about disaggregated performance fragmented in their Organisation, divided in their collective action, more in competition with the colleagues, greater mobility of labour and enhanced individual capacity to bargain for income and incentives, thus, individualising work.

Carol and Vasavi (2006) find dimension of Indian software labour market as:

i) Mobility: The software workforce is highly mobile geographically and between companies for its work and career within India and abroad.

ii) Flexibility: The global and competitive nature of the IT industry requires flexibilisation of work process, organisation and employment (part-time or contract). Flexibility within the companies is maintained through 'resource management' systems where employees are classified as billable or non-billable resource.

iii) Individualisation: Flexibility and mobility of the workforce lead to individualisation. Individualisation is defined as an orientation in which people centre their planning and actions around themselves based on their self-interest rather than around collectivities. The emergence of individualised employment relations among the software workers is due to absence of collective identity, high level of attrition and their tendency to build up careers by job hopping.

\section{Micro level}

In the Network Enterprise, work-force is an important resource for productivity, innovation and competitiveness. The individual is dependent on labour market and it is the labour market that shapes the individual identity. 
Castells (1997) points out as to how self-programmable labour ${ }^{13}$, who works on Net, develop a distinct kind of identity ${ }^{14}$ of self. Identity of people is increasingly organised not around 'what they do' but on the basis of 'what they are, or believe they are'. The workforces need to match their portfolio careers. They are entrusted total commitment for the business projects i.e. they need to keep it up with their project-based work-lives that may necessitate expanded working hours. Henceforth, their identity is structured around binary logic based on in/out, switch on/off as individuals, groups, regions and countries and structured for fulfilling project goals of network. Therefore, the workforces do not develop any strong sense of local or national or organisational identity in relation to a particular firm. Consequently, a new system of social relationship emerges centered round the individual i.e. me-centered (tertiary relationships). It is a specific pattern of sociability i.e. individualised relationship to the society rooted in the individualisation of relationship within the workplace between the workers and the work process replacing primary relationships (embodied in families and communities) and secondary relationships (embodied in associations). The author points out that this leads to crisis in patriarchalism and traditional nuclear family. Castells (2001) further observes that the emergence of new pattern of sociability is centered on networked individualism where individuals build their networks, on-line and off-line, on the basis of their interests, values, affinities and projects.

\subsection{Female Workforce:-}

Hochschild and Machung (1989) observed that in the earlier economy, female labour force has two shifts viz. the $1^{\text {st }}$ shift in office and the $2^{\text {nd }}$ shift at home. But, actually, women more often juggle between three shifts i.e. Job, Childcare and Housework whereas the men juggle between jobs and childcare. Hochschild (1997) later propounded the idea of a 'third shift' in conformity with the call for the New Economy. Longer working hours at the office in the first shift (at workplace) often encroach on the family time i.e. the second shift (at home) i.e. needs to be hurried and rationalised. The situation forces the parents to engage themselves in a 'third shift' i.e. noticing, understanding and coping with the emotional consequences of the compressed second shift. Parents do make real effort to eliminate the 'wasted time'. The more attached they are to the world of work, the more its deadlines, its cycles, its pauses and interruptions shape their lives and the more family time is forced to accommodate the pressures of work. The problem of time bind causes shortfall of time for being devoted to private social relations (Hochschild 1997). Hochschild and Machung, 1989, raised concern over the fact that entrance of men into industrial work did not destabilise the family but the rise in female employment has increased the divorce rate. Hochchild speaks of 'stalled revolution' as it puts strain on women while they change with the demands of workforce without corresponding change in other spheres; like inflexibility in the workplace vis- $a$ vis demands at home and men being adapt less to the changes. 'Stalled revolution' has its root in the lack social arrangements that ease life for the working parents and men usually failing to share the second shift.

Beck (1998) points out that woman with equal educational opportunities followed by increased awareness of their positions, build up expectation of more equality and partnership in professional as well as family life, is in contradiction to both of labour market and male behaviour. Men and women in double-income model have two individual biographies- education, job and career. It results in conflicts between men and women in marriage to open up possibilities to choose (diverging professional mobility of spouses, division of housework and child care, type of contraception and sexuality). Process of individualisation makes men and women, released from traditional forms and ascribed gender roles, searching for a life of their own against equal educational opportunity for women. For about three decades the women's life has been rendered like an 'empty nest' by the use of contraceptive, family planning measures, legal termination of pregnancies etc. liberating them from traditional demand of motherhood. The child is viewed as an impediment in the individualisation process. It costs money and work. Deskilling of housework (technical automation and paid services) directs women towards work outside the home. Earning women, freed from lifelong support from husband, are exposed to the fragility of marital and family support leads to rise in divorce. The labour market, demands constant mobility of workforce without regard to personal circumstances as also market model of modernity imply a society without families and children. For women, marriage means renunciation of their career, responsibility for the children and co-mobility according to the professional destiny of their husbands (Beck 1998).

Emerging individualisation phenomena of the labour market implies liberating women from patriarchal constraints. Walby Sylvia defines 'patriarchy as a system of social structures and practices, in which men dominate, oppress and exploit women' (1991:21). She refers to the term 'social structure' that predetermines every individual man in a dominant position and every woman in a subordinate one. Patriarchy, conceptualised at different levels of abstraction, exists as a system in social relations. There exists two major forms of patriarchy; private patriarchy based on household production that was dominant in the 19C, when individual patriarchs expropriated women's labour and oppressed them. The other form is the public patriarchy that was predominant in $20^{\text {th }} \mathrm{C}$ was the in public arena such as employment or state; where collective appropriation takes place. In both the private and public patriarchy, the principal patriarchal strategy was exclusionary and segregationist/subordinating respectively. Due to this strategy, she argues that men and women typically do not 
work in the same occupations or industries. Women are not only concentrated in the lower grades of work (vertical segregation), but in different areas of work (horizontal segregation). Walby further cites, Hartmann, $1979^{15}$, who viewed patriarchal relation to be understood in terms of gender relations at the workplace. He distinguishes two patriarchal strategies in the workplace as exclusion and segregation. Exclusion strategy aimed at totally preventing women's access to an area of employment, or to all paid employments and segregation aimed at separating women's work from that of men by treating the former beneath the later in respect of remuneration and status.

\section{Structural level model-forces of change through globalisation}

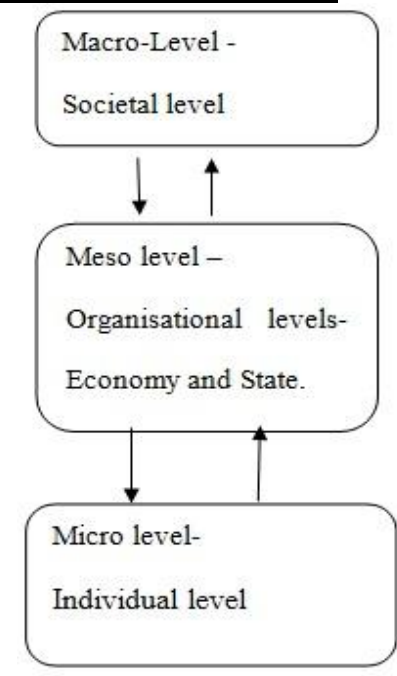

Source: Author's adaptation of the model

\section{Discussion}

In India the post-liberlisation era paved the way for the development of IT Industry. It has been the dream of many young job seekers to get into the sector. It has provided job opportunity for very young technical as well as non-technical graduates in a very comfortable and conducive office environment and with handsome pay-package together with prospects of foreign travel. It unfolds actually the American dream to the GenX middle class population including substantial part of women folk.

This paper essentially starts with the objective question as to what extent women in IT enjoy opportunities and whether they are facing any kind of constraints.

The secondary literature based on empirical study on women workforce in IT sector reveals that this sector has undoubtedly enhanced the social mobility and high work participation of women employees in catching up with the direct opportunities provided by IT. It has further enhanced the financial autonomy and bargaining capacity in the household decision-making process for the women. The individualising capacity practiced in the workplace helped in redefining traditional gender norms. Women working in IT have moreover, enhanced the 'symbolic capital' that increases their social status in the marriage market as potential brides by re-defining feminity. Nayar (2007) observed that opportunities at the job market inspired female students to take up technical and professional courses to rise to the demands of the labour market. Carol, 2006, points out that women in this sector are able to break technical arena, which has so long being a male bastion. Clark and Shekher (2007) again points out that the effects of this 'IT' hype resulted in double-income family replacing the single 'male breadwinner' model. Parents now tend to 'give equal importance to girls' education like that of their boys to enable girls to pursue their own career and financial independence rather than being dependent on others in the family for playing the roles of housewives and mothers. Women feel themselves empowered vis-à-vis disempowerment of their parents, since they were unable to achieve the careers, they desired, although they have education, extends a positive demonstrative effect.

Women gradually prefer to work outside home in an attempt to improve upon their social position rather than bearing with dependency and coercion in the family (Kelkar and Nathan 2002).

The literatures reveal that though at the policy level 'the principle of Equal opportunity' for women's employment is slated to be followed, yet the field studies show that in practice women stagnate at certain lower hierarchy ranks such as entry and middle level in the job ladder and concentrated in certain specific areas like HR, Call centers, marketing, financial sector etc. The results reflect that the gender relation at the workplace projecting certain kind of stereotypical image of women workforce and societal constraints force them in experiencing glass- ceiling causing over-representation in certain job segments in the lower rung while there is scant 
representation of women in the top level of the hierarchy. To sum up, the theoretical framework starts with the globalising forces having changed the society from traditional to modern and from modern to high modern societies at Macro level and how the very context of individual identity is changing by holding tradition in limbo. We have already observed as to how Globalisation has changed the economic institution and political fervor to suit the need of the market at Meso level. The dimension of labour market has strong impact on the workforce in liberating Individualising phenomenon. At micro level, the discussion highlights as to how an informed labour market shapes the identity of individual where ' $\mathrm{I}$ ' is an important component and improvises social relations.

Individualisation of women workforce in the workplace has liberated them from traditional gender roles and ascribed demands. This again, exposes them to the risks of divorce, intra family conflict and even destabilising the family. It has also been seen that the work-place constraints for women employees includes, inter alia, patriarchal relation is in existence in the form of exclusion and segregation though not intended at the policy level set up.

The entire discussion leaves with the question 'Are women in IT sector in India, is liberated or is still in patriarchal bindings'?

\section{Way forward:}

The entire discussion forum opens up many arenas where future research may be carried out. The future research may look into the transition from tradition to modernity or the whole gamut of private/public patriarchy that the women workforce unravels. Also, the risks or effects of this change may well be gauged.

Notes:

1. The software services industry is often referred to generically as the 'IT' (Information Technology) industry, although technically 'IT' includes hardware as well as software. But in India it is popularly called software industry.

2. NASSCOM-Mencher Report, 2009 and Shanker, 2008.

3. The term 'glass ceiling' gained momentum in 1980s when the issue of gender difference in career and under-representation in senior management gained prominence. Arflen et al. (2004) defines it like glass walls that restrict women to certain fields and positions, such as human resource management and other staff duties. Women are held back from corporate advancement due to lack of informal network of communications, prejudiced male preconceptions and stereotyping of women in certain organisation.

4. Shanker, 2008 quotes Wajcman, 1998 for definition of 'glass ceiling' referring to the invisible barriers obstructing women's promotional opportunities, impeding the women's upward mobility beyond the middle level of management. 'Glass ceilings' for women were the consequence of gap between policies and their actual implementations. She further asserted that 'glass ceilings' could be determined at the 'structural level'/formal level i.e. at the level of organisational practices or at symbolic level i.e. 'informal barriers' i.e. in facilities, signs and actions by which gender differences are performed and made visible.

5. Vide Giddens A (1991): Modernity and Self identity; Self and Society in Late Modern Age; Giddens A.(1994): 'Living in a post Industrial Society' in Beck, Giddens and Scott edited book; Giddens A (2000): Runaway World; for further discussion.

6. The term 'risk society' used by Beck (1998) denotes radicalistion of modernity which breaks up promise and contour of industrial society giving rise to the risk society.

7. Self, as reflexively understood by a person, in terms of her or his biography (Giddens, 1991).

8. Ontological security is a stable mental state derived from a sense of continuity in regard to the events in one's life (Giddens, 1991).

9. Risk refers to probability and uncertainty. 'Risk refers to hazards that are actively assessed in relation to future possibilities. Risk is perceived in a society which is future oriented -which sees the future precisely as a territory to be conquered or colonised. Risk presumes a society that actively tries to break away from its past' (Giddens 2000).

10. Individualisation refers to certain subjective-biographical aspects of the civilisation process. Individualisation expectations are aroused in the form of a desire for a 'life of one's own (in material, temporal and spatial terms and in structuring social relationships) resulting in search of social and personal identities and commitments in detraditionalised culture. It contradicts the process of socialisation (Beck 1998).

11. 'Toyatism' emphasise on flat management hierarchy or horizontal cooperation i.e. consensusbuilding, cooperative model of team-work, greater autonomy of decision of the worker and prioritised process not tasks.

12. Taylorism implies vertical integration and social and technical division of labour.

13. Self-programmable labour is a highly educated networker, i.e. who works by networking and works on the net and their unit of work is the project (Castells 1997). 
14. Castells, 1997, defines identity as the process by which a social actor recognises itself and constructs the meaning primarily on the basis of a given cultural attribute or set of attributes, to the exclusion of a broader reference to other social structures.

15. Sylvia's understanding of Hartmamn is based on the book 'Hartmann, H. (1979) "Capitalism, Patriarchy and Job Segregation by Sex," in Z. R. Eisentein (ed.), Capitalist Patriarchy and Case for Socialist Feminism, New York: Monthly Review Press, 206-47.

\section{References}

[1] Abraham, Margaret, 'Globalisation and the Call Center Industry', International Sociology, 23 (2), $2008,197-210$.

[2] Arfken, D. E., S. L. Bellar, M. M. Helms, 'The Ultimate Glass Ceiling Revisited: The Presence of Women on Corporate Boards', Journal of Business Ethics, 50 (2), 2004, 177-86.

[3] Beck, Ulrich, Risk Society: Towards New Modernity. London: Sage, 1998Clark, A.W. and T. V. Sekher, 'Can Career-Minded Young Women Reverse Gender Discrimination? A View from Bangalore's High-Tech (5) Sector', Gender, Technology and Development, 11 (3), 2007, 285-319.

[4] Castells, Manual, Rise of Network Society: The Information Age: Economy, Society and Culture, Vol. I. USA: Blackwell publishers Inc. 1997.

[5] Castells Manual, The Internet Galaxy: Reflections on the internet, business and Society. USA: Oxford University Press, 2001.

[6] Friedman, Thomas L, The World is Flat: a brief history of the twenty-first century. New York: Farrar, Straus and Giroux, 2006.

[7] Giddens, Anthony, Modernity and Self identity: Self and Society in Late Modern Age. Standford California: Standford University Press, 1991.

[8] Giddens, A. 'Reflexive Modernisation: Politics, Tradition and Aesthetics in the Modern Social order', in Beck Ulrich, Giddens Anthony and Lash Scott (eds.): Living in a post Industrial Society, London: Stanford University press, (56-107), 1994.

[9] Giddens, Anthony, Runaway World. New York: Routledge, 2000.

[10] Hochschild, Arlie. and A. Machung, The Second Shift: Working parents and the Revolution at Home. New York. Viking Penguin Inc. 1989.

[11] Hochschild, Arlie, The Time Bind: When work becomes home and home becomes work. New York: Metropolitan Books, 1997.

[12] Kelkar, G., G. Shrestha, and N. Veena, 'IT Industry and Women's Agency: Explorations in Bangalore and Delhi, India', Gender, Technology and Development, 6(1), 2002, 63-84.

[13] Kelkar, G. and D. Nathan, 'Gender Relations and Technological Change in Asia', Current Sociology, 50(3), 2002, 427- 441.

[14] Kumar, Nagesh, 'Indian Software Development: International Perspective', Economic Political Weekly, 36(45), 2001, 42784290.

[15] NASSCOM-Mencher, Gender Inclusivity in India: Building Empowered organisation. New Delhi: NASSCOM, 2009.

[16] Nayyar, Deepak, 'Globalisation: What Does It Mean for Higher Education?', Economic Political Weekly, 42(50), $2007,30-35$.

[17] Scott Lash, 'Reflexive Modernisation: Politics, Tradition and Aesthetics in the Modern Social order' in Beck Ulrich, Giddens Anthony and (20) Lash Scott (eds.): Reflexivity and its Doubles: Structure, Aesthetics, Community, Society, London: Stanford University press, 1994, 110-162.

[18] Sassen, Saskia, Losing Control? Sovereignty in an age of Globalisation. New York: Columbia University Press, 1996.

[19] Shanker, Deepika, 'Gender Relations in IT Companies: An Indian Experience', Gender, Technology and Development, 12 (2), 2008, 185- 207.

[20] Upadhya, Carol, 'Gender in the Information Society: Emerging Issues' in Gurumurthy Anita, P. J. Singh, A. Mundkur and M. Swamy (eds.), Gender issues in the Indian Software Outsourcing Industry, 2006, (24) 74-84.

[21] Upadhya, Carol and Vasavi A.R, Work, culture and Sociality in the Indian IT Industry: A Sociological study, Report submitted to Indo-Dutch Programme for Alternatives in Development, NIAS, Bangalore, 2006.

[22] Walby, Sylvia, 1991.Theorising Patriarchy, UK: Basil Blackwell Ltd, 1991 